\title{
Comparison between Pseudomonas aeruginosa siderophores and desferrioxamine for iron acquisition from ferritin
}

\author{
Somporn Srifuengfung ${ }^{\mathrm{a}}$, Susan Assanasen ${ }^{\mathrm{b}}$, Malulee Tuntawiroon ${ }^{\mathrm{c}}$, Sumonrat Meejanpetch ${ }^{\mathrm{a}}$ \\ ${ }^{a}$ Department of Microbiology, ${ }^{b}$ Department of Medicine, ${ }^{c}$ Department of Nuclear Medicine, Faculty \\ of Medicine Siriraj Hospital, Mahidol University, Bangkok 10700, Thailand
}

\begin{abstract}
Background: Siderophore is an iron chelator produced by microorganism. Pseudomonas aeruginosa produces two siderophores (pyoverdin and pyochelin). Desferrioxamine is a siderophore used in thalassemia patients to treat an iron overload of vital organs.

Objective: Compare the ability of pyoverdin, pyochelin, and desferrioxamine for iron mobilization from ferritin. Materials and Methods: In vitro experiment, the ability of P. aeruginosa siderophores and desferrioxamine for iron mobilization from ferritin was compared by using a dialysis membrane assay at $\mathrm{pH}$ values of 7.4 and 6.0. Stimulation of $P$. aeruginosa PAO1 growth by all siderophores was studied in glucose minimum medium.

Results: All three compounds were capable of iron mobilization at both $\mathrm{pHs}$. At $\mathrm{pH}$ 6.0, the most effectiveness compound was desferrioxamine (31.6\%), followed by pyoverdin (21.5\%) and pyochelin (13.7\%) compared on weight basis, each at $10 \mu \mathrm{g} / \mathrm{mL}$. At equimolar concentration, their activities were desferrioxamine $(38.5 \pm 1.2 \%)$, followed by pyoverdin (32.0 $\pm 4.8 \%)$ and pyochelin $(26.7 \pm 1.9 \%)$, respectively.

Conclusion: The most effective compound in iron mobilization from ferritin was desferrioxamine, followed by pyoverdin and pyochelin respectively.
\end{abstract}

Keywords: Desferrioxamine, ferritin, Pseudomonas aeruginosa, pyochelin, pyoverdin, siderophores

Thalassemia occurs widely throughout Africa, the Mediterranean countries, the Middle East and Southeast Asia including Thailand. Currently, thalassemia is one of the important health problems worldwide as it results in health, social, and economic problems $[1,2]$. The incidence rate of thalassemia in Thai people is approximately $1 \%$ of the population and increases when thalassemia carriers are included [3]. Lifelong transfusion therapy of thalassemia patients leads to progressive iron overload of vital organs. This ultimately fatal condition can only be treated by continuous chelation therapy with drugs, which increase the excretion of excess iron via the kidneys. From several hundred potential chelating

Correspondence to: Somporn Srifuengfung, Ph.D, Department of Microbiology, Faculty of Medicine Siriraj Hospital, Mahidol University, Bangkok 10700, Thailand. E-mail: sissf@ mahidol.ac.th agents tested, desferrioxamine mesylate, USP (deferoxamine) with the trade name of Desferal (Ceiba Geigy Co, Switzerland), has proved to be the best safe and clinically effective drug. Iron is important for all living cells. Siderophores are low-molecular weight iron chelating compounds produced in response to iron deprivation by micro-organisms and excreted for binding and uptake of iron into their cells. The two main structural types of siderophores are phenolate type (water-insoluble) and hydroxamate type (watersoluble). Some bacteria may produce siderophores of one or both types [4]. Desferal is a siderophore produced by fermentation using Streptomyces pilosus and is extracted by an elaborate and expensive recovery process. The complex mode of production and the need for frequent administration in gram amounts by slow infusion into thalassemia patients, all contribute to the considerable overall cost of treatment. Desferal cannot be given orally. 
Development of more convenient forms of administration for Desferal and the search for cheaper, orally active drugs have been the prime targets of many research groups. Several interesting candidates have been described and investigated further $[5,6]$. None has yet been shown to be a perfect drug. The important property of all siderophores is stimulation of bacterial growth in an iron-limiting medium.

This study aimed to provide the comparative data between $P$. aeruginosa siderophores i.e., pyoverdin (hydroxamate type) and pyochelin (phenolate type) $[7,8]$, and desferrioxamine on iron mobilization from ferritin that is the main intracellular storage protein for iron, and has the stimulation effect on bacterial growth. The term iron mobilization was used to indicate the conversion of unavailable iron bound to ferritin into siderophore-bound iron.

\section{Materials and methods}

Purified siderophores were generously provided by Professor Charles D. Cox, The University of Iowa, USA. Human ferritin was purchased in substantially iron-free form (Sigma Chemical Co, USA). Desferrioxamine mesylate, USP was obtained in purified standard powder (Ceiba-Geigy Co, Basle, Switzerland). A dialysis membrane assay to detect iron mobilized from ferritin by siderophores was determined according to a previous report [9]. This test detects the ability of siderophores and desferrioxamine to mobilize ${ }^{59} \mathrm{Fe}$ from $\left[{ }^{59} \mathrm{Fe}\right]$ ferritin because siderophores and desferrioxamine are small molecular weight (MW) compounds i.e., 325 for pyochelin [10], 1,333 for pyoverdin [11] and 638 for desferrioxamine [12]. The M.W. of ferritin is approximately 480,000 [13]. $\left[{ }^{59} \mathrm{Fe}\right]$ ferritin was put on one side of a dialysis membrane (MW size exclusion $8,000)$, the so-called ferritin side. Siderophores and desferrioxamine were put on the opposite side, the so-called dialysate side. If they mobilized iron, they would pick up radioactivity from $\left[{ }^{59} \mathrm{Fe}\right]$ ferritin and carry the radioactivity back to the dialysate side to establish the equilibrium. Therefore, the radioactivity would appear in samples taken from the dialysate side. The $\left[{ }^{59} \mathrm{Fe}\right]$ ferritin side consisted of ferritin $(100 \mu \mathrm{g} /$ mL) $45 \mu \mathrm{L},{ }^{59} \mathrm{Fe} 5 \mu \mathrm{L}(0.05 \mu \mathrm{Ci}, 110,000 \mathrm{dpm})$, Tris buffer $(50 \mathrm{mM}) 50 \mu \mathrm{L}$, and distilled water $400 \mu \mathrm{L}$. The dialysate side consisted of $500 \mu \mathrm{L}$ of buffer and either siderophores or desferrioxamine was added at a final concentration of $10 \mu \mathrm{g} / \mathrm{mL}$. All experiments were conducted in a low temperature shaking incubator (Model Amerex Instrument, USA, Gyromax $707 \mathrm{R}$ ) at a rate of $30 \mathrm{rpm}, 4^{\circ} \mathrm{C}$ and performed in triplicates. After 48 hours of incubation, $400 \mu \mathrm{L}$ samples were removed from the dialysate side to measure the ${ }^{59} \mathrm{Fe}$ radioactivity in the low-molecular weight chelates, which diffused through the membrane by scintillation gamma-counter. Tris buffer was used at $\mathrm{pH} 7.4$ and 6.0.

Bacterial growth test was determined using a glucose minimum medium (GMM) consisting of $20 \mathrm{mM}$ glucose, $40 \mathrm{mM}$ ammonium acetate and $5 \mathrm{mM}$ potassium phosphate buffer ( $\mathrm{pH}$ 7.4). All glassware was soaked in concentrated nitric acid and rinsed extensively with deionized water. P. aeruginosa PAO1 (ATCC 15692 from the American Type Culture Collection, Rockville, USA) was prepared for inoculum by using casamino acid medium which contained $0.5 \%$ casamino acid (Difco Co, USA) supplemented with $0.4 \mathrm{mM} \mathrm{MgCl}{ }_{2}$ [9]. Bacteria were harvested from the culture by centrifugation at 7,500 rpm for 20 minutes. Then, they were washed three times in sterile deionized water and inoculated at a final concentration of approximately $10^{3} \mathrm{CFU} / \mathrm{mL}$. Bacteria growth in GMM was estimated by measuring $\mathrm{A}_{600}$ with a spectrophotometer (Model UV/Vis OPRON-3000, Daiki Sciences Co, Seoul, Korea). Colony plate counts of $P$. aeruginosa PAO1 at 0 hour and 18 hours of incubation in GMM containing $10 \%(\mathrm{~V} / \mathrm{V})$ heatinactivated $\left(56^{\circ} \mathrm{C}\right.$ for 30 minutes) normal human serum from a pool obtained from 10 blood donors were performed by spreading $0.1 \mathrm{~mL}$ of each bacterial suspension on triplicate plates of trypticase soy agar and incubating for 24 hours at $35^{\circ} \mathrm{C}$.

\section{Results}

The result of this study showed that all three compounds were capable of iron mobilization at $\mathrm{pH}$ values of 7.4 and 6.0 ( $p<0.05$ compared with control). At $\mathrm{pH}$ 6.0, the most effectiveness compound was desferrioxamine $(31.6 \%)$, followed by pyoverdin $(21.5 \%)$ and pyochelin (13.7\%) when compared on weight basis, each at $10 \mu \mathrm{g} / \mathrm{mL}$ (Table 1). At equimolar concentration of .0075 $\mu \mathrm{mol} / \mathrm{mL}$ (Table 2), their activities were desferrioxamine $(38.5 \pm 1.2 \%)$, followed by pyoverdin $(32.0 \pm 4.8 \%)$ and pyochelin $(26.7 \pm 1.9 \%)$.

In bacterial growth testing, all three compounds were effective in promoting bacterial growth in GMM compared to control (Fig. 1). 
Table 1. Comparison between pyoverdin, pyochelin, and desferrioxamine in iron mobilization from $\left[{ }^{59} \mathrm{Fe}\right]$ ferritin.

\begin{tabular}{|c|c|c|c|c|c|c|c|c|}
\hline \multirow[t]{2}{*}{ Tris buffer } & \multirow{2}{*}{$\begin{array}{l}\text { Control } \\
\text { dpm }^{*}\end{array}$} & \multirow[b]{2}{*}{$\begin{array}{l}\% \\
\text { Mobilized }\end{array}$} & \multicolumn{2}{|c|}{ Pyoverdin } & \multicolumn{2}{|c|}{ Pyochelin } & \multicolumn{2}{|c|}{ Desferrioxamine } \\
\hline & & & dpm & $\begin{array}{l}\% \\
\text { Mobilized }\end{array}$ & dpm & $\begin{array}{l}\% \\
\text { Mobilized }\end{array}$ & dpm & $\begin{array}{l}\% \\
\text { Mobilized }\end{array}$ \\
\hline $\mathrm{pH} 7.4$ & 7,463 & 6.8 & 15,276 & 13.9 & 16,250 & 14.8 & 22,224 & 20.2 \\
\hline $\mathrm{pH} 6.0$ & 4,301 & 3.9 & 23,603 & 21.5 & 15,037 & 13.7 & 34,724 & 31.6 \\
\hline
\end{tabular}

*disintegration per min, mean values of triplicate experiments.

Table 2. Comparison between pyoverdin, pyochelin, and desferrioxamine in iron mobilization from $\left[{ }^{59} \mathrm{Fe}\right]$ ferritin in Tris buffer $\mathrm{pH} 6.0$ by equimolar concentration.

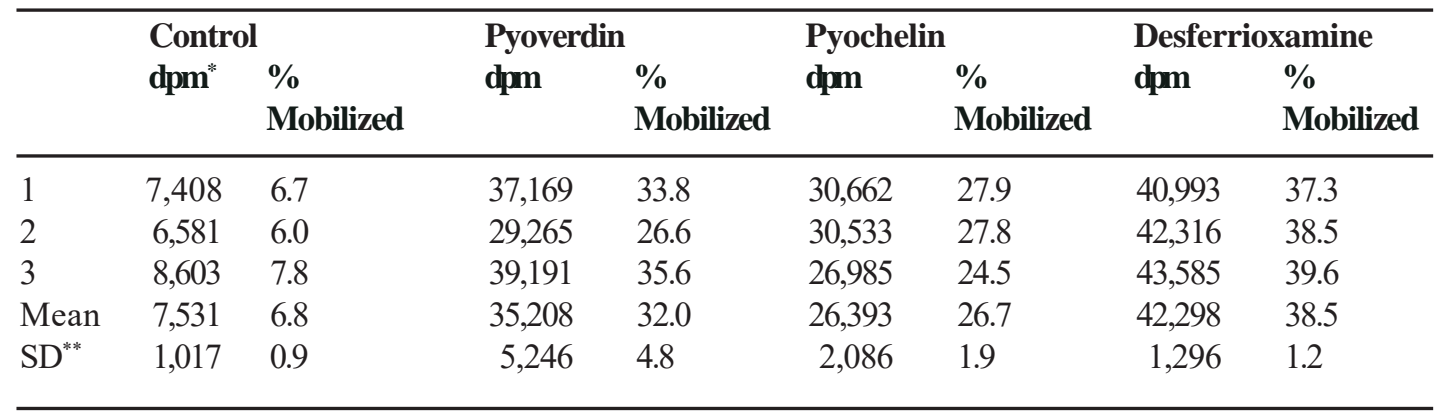

*disintegration per minute. ${ }^{* *}$ Standard deviation.

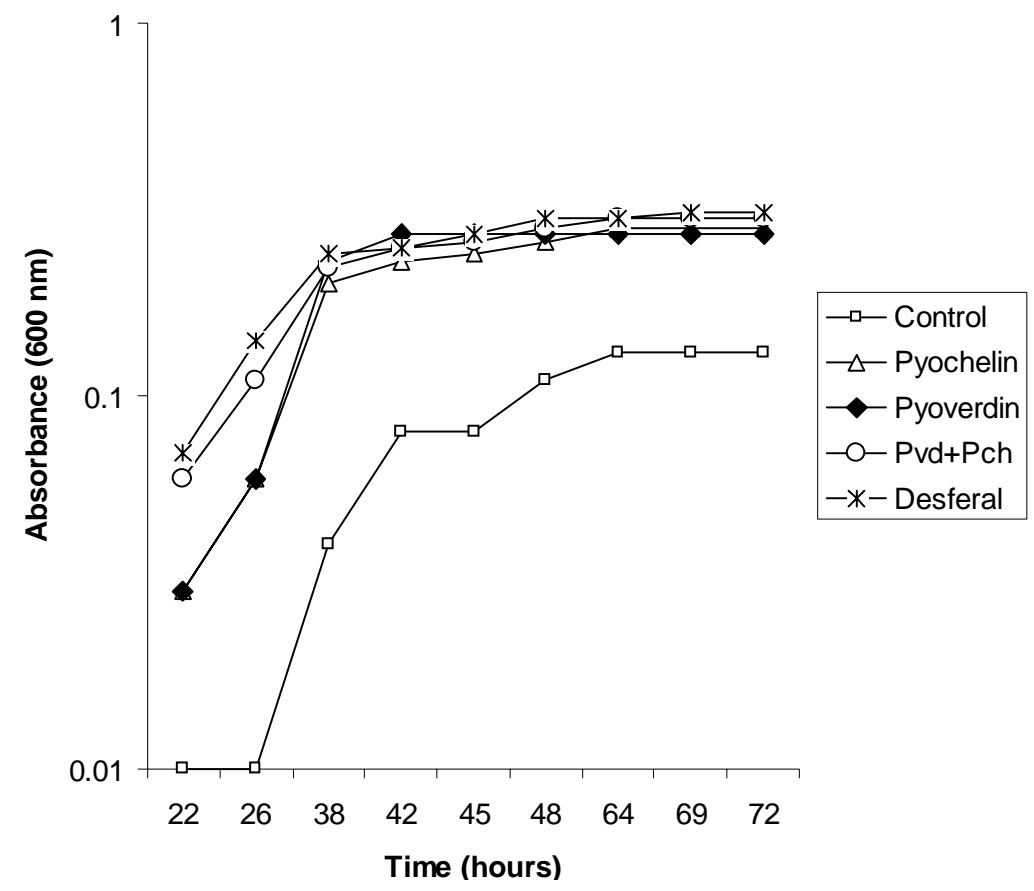

Fig. 1 Effect of siderophores and desferrioxamine on bacterial growth in GMM.

A similar result was found in GMM containing 10\% (V/V) heat-inactivated human serum (Table 3). However, the interesting result from the bacterial growth assay in was that pyoverdin was active promoting growth in human serum to the same extent as desferrioxamine. Pyochelin was less capable of stimulating bacterial growth. 
Table 3. Effect of siderophores and desferrioxamine on colony plate count in GMM containing 10\% heat-inactivated serum.

\begin{tabular}{lllll}
\hline Incubation & \multicolumn{4}{c}{ Colony plate count (CFU/mL) } \\
\hline & Control & Pyoverdin & Pyochelin & Desferrioxamine \\
\hline At 0 hour & $3.10 \times 10^{2}$ & $2.90 \times 10^{2}$ & $2.70 \times 10^{2}$ & $2.8 \times 10^{2}$ \\
At 18 hours & $1.73 \times 10^{8}$ & $3.53 \times 10^{12}$ & $8.86 \times 10^{9}$ & $4.3 \times 10^{12}$ \\
\hline
\end{tabular}

\section{Discussion}

The pH 6.0 was chosen for the sake of comparison of siderophore activity and because this $\mathrm{pH}$ has been found to exist in inflammatory exudates [14]. We added the siderophores to the test system at $10 \mu \mathrm{g} / \mathrm{mL}$ because at this concentration, it is approximate to the concentration that could be found in casamino acid medium culture filtrate $[13,15]$. To our knowledge, this is the first report of iron acquisition from ferritin by $P$. aeruginosa siderophores.

In nature, ferritin is composed of an apoprotein shell that surrounds a core of up to 4,500 atoms of iron [12]. The recovery of iron from ferritin in the cell is crucial for biosynthesis and is of great interest to medical research because the safe removal of iron from ferritin is a goal of chelation therapy. In vitro experiments showed that iron mobilization occurred in the presence of $\mathrm{Fe}^{+3}$ chelators or reductants. Whether chelators and reductants penetrate the ferritin molecule has been a matter of controversy [16]. In addition to bacteria, Candida albicans was reported to acquire iron from ferritin by using hyphalassociated adhesion and invasin [17].

The results of siderophores stimulating bacterial growth correlated with the binding coefficients of the siderophores for iron. The iron binding coefficients of pyoverdin and desferrioxamine are $10^{32}[11]$ and $10^{31}$ [12], respectively, which are much higher than that of pyochelin, which is $5 \times 10^{5}$ [18]. Our result agrees with previous report that pyoverdin appears to be the most important siderophore of $P$. aeruginosa for growth in human serum [15].

Several siderophore analogues have been chemically synthesized. Interestingly, $P$. aeruginosa siderophore analogues produced by the biological method of mutasynthesis were reported for pyochelin [19]. In vitro iron acquisition from transferrin or lactoferrin by pyoverdin at physiological $\mathrm{pH}$ was reported [20].

In conclusion, pyoverdin may be important for development of drug for treatment of iron overload in thalassemia patients. Other pyoverdins produced by environmental Pseudomonas species need to be further studied.

\section{Acknowledgements}

We are indebted to Professor Sutat Fucharoen for his suggestion to initiate this research. We are grateful to Professor Charles D. Cox, The University of Iowa, USA for providing the purified pyoverdin and pyochelin. This study was supported by the grants from Thailand Research Institute and the Faculty of Medicine Siriraj Hospital, Mahidol University. The authors have no conflict of interest to report.

\section{References}

1. Vichinsky EP. Changing patterns of thalassemia worldwide. Am NY Acad Sci. 2005; 1054: 18-24.

2. Fucharoen S, Winichagoon P. Prevention and control of thalassemia in Asia. Asian Biomed. 2007; 1:1-6.

3. Panich V, Pornpatkul M, Sriroongrueng W. The problem of thalassemia in Thailand. Southeast Asian J Trop Med Public Health. 1992; 23(Suppl 2):1-6.

4. Yang H, Kooi CD, Sokol PA. Ability of Pseudomonas pseudomallei malleobactin to acquire transferrinbound, lactoferrin-bound, and cell- derived iron. Infect Immun. 1998; 61:656-62.

5. Franchini M, Veneri D. Iron-chelation therapy: an update. Hematology J. 2004; 5:287-92.

6. Neufeld EL. Oral chelators deferasiox and deferiprone for transfusional iron overload in thalassemia major: new data, new questions. Blood. 2008; 107:3436-41.

7. Cox CD. Iron uptake with ferripyochelin and ferric citrate by Pseudomonas aeruginosa. J Bacteriol. 1980; 142:581-7.

8. Cox CD, Adams P. Siderophore activity of pyoverdin for Pseudomonas aeruginosa. Infect Immun. 1985; 48:130-8.

9. Sriyosachati S, Cox CD. Siderophore-mediated iron acquisition from transferrin by Pseudomonas aeruginosa. Infect Immun. 1986; 52:885-91.

10. Cox CD, Rinehart KL, Moore ML, Cook JCJr. 
Pyochelin: novel structure of an iron-chelating growth promoter for Pseudomonas aeruginosa. Proc Natl Acad SciUSA. 1981; 78:4256-60.

11. Wendenbaum S, Demange P, Dell A, Meyer JM, Abdallah MA. The structure of pyoverdin $\mathrm{Pa}$, the siderophore of Pseudomonas aeruginosa. Tetrahedron Lett. 1983;24:4877-80.

12. Heinrich HP. The present state of iron-chelation therapy. In: Aksoy M, Birdwood GB, editors. Hypertransfusion and iron chelation in thalassemia. Stuttgart (Toronto):Hans Huber; 1985. p. 69-81.

13. Brock JH, Halliday JW, Pippard MJ, Powell LW. Iron metabolism in health and disease. London:WB. Saunders. 1994. p. 24-8, p. 63-5.

14. Menkin V. The role of the hydrogen ion concentration and the cytology of an exudate glycolysis in inflammation. Some aspects of the chemistry of exudates. In: Ryan EJ, editor. Biochemical mechanisms in inflammation. Springfield:Charles.C Thomas. 1956. p. 66-103.

15. Ankenbauer R, Sriyosachati S, Cox CD. Effects of siderophores on the growth of Pseudomonas aeruginosa in human serum and transferrin. Infect
Immun. 1985; 49:132-40.

16. Castruita M, Elmegreen LA, Shaked Y, Stiefel EI, Morel FMM. Comparison of the kinetics of iron release from a marine (Trichodesmium erythraeum) Dps protein and mammalian ferritin in the presence and absence of ligands. J Inorg Biochem. 2007; 101:1686-91.

17. Almeida RS, Brunke S, Albrecht A, Thewes S, Laue M, Edwards JE, et al. The hyphal-associated adhesion and invasin Als of Candida albicans mediates iron acquisition from host ferritin. PLos Pathog 4, e1000217 (online), 2008. [cited 2008 Nov 21]. Available at: http:// www.plospathogens:org/article/info:doi\%2F10.1371\% 2Fjournal.ppat.1000217.

18. Cox CD, Graham R. Isolation of an iron-binding compound from Pseudomonas aeruginosa. J Bacteriol.1979; 137:357-64.

19. Ankenbauer R, Staley AL, Rinehart KL, Cox CD. Mutasynthesis of siderophore analogues by Pseudomonas aeruginosa. Proc Natl Acad Sci USA. 1991; 88:1878-82.

20. Xiao G, Kisaalita WS. Iron acquisition from transferrin and lactoferrin by Pseudomonas aeruginosa pyoverdin. Microbiology. 1997. 143: 2509-15. 